\title{
English Proficiency and Academic Achievement in the Philippines ESL Contexts
}

\author{
CHEN Bing \\ College of Foreign Languages, Guangxi University, China \\ Received: April 10, $2021 \quad$ Accepted: May 6, $2021 \quad$ Published: August 30, 2021
}

To cite this article: CHEN Bing. (2021). English proficiency and academic achievement in the Philippines ESL contexts. Asia -Pacific Journal of Humanities and Social Sciences, 01:2, 035-047, DOI: 10.53789/ j.1653-0465.2021.0102.004

To link to this article: https://doi.org/10.53789/j.1653-0465.2021.0102.004

\begin{abstract}
The extant literature has focused on the factors which impacted the individuals' academic achievement such as intercultural communication, acculturation, motivation and attitude etc. However, research on individuals' English language proficiency and its impacts on college students' academic achievement and identity need to be taken into account. Based on second language acquisition theory, using a case study with mixed methods, this article conducted the questionnaire survey and in-depth interviews. The results of the study indicate that there is not always a clear relationship between English language proficiency and academic achievement; the participants are willing to communicate in English; the English language is in relation to identities construction and negotiation. The implications of this study highlight the need to study the other factors which impact the ESL learners' academic achievement. Based on the findings, contributions to theory and practice, limitations, and future directions are discussed in conclusion.
\end{abstract}

Keywords: English language proficiency; academic achievement; identities; the Philippines; ESL context

Notes on the contributor: CHEN Bing is currently a professor of College of Foreign Languages, Guangxi University, and a deputy editor-in-chief of Asia Pacific Interdisciplinary Translation Studies.

\section{Introduction}

This study is important as it attempts to explore the impacts of English language proficiency on academic achievement, and the relation between the English language and its identities construction and negotiation in the Philippine ESL context. This is an on-the-spot investigation which has been conducted with a quantitative questionnaire survey and in-depth qualitative interviews with the participants. With its English literacy rate of 98\% (World Bank), the Philippines is home to the largest English speaking population in Southeast Asia today and therefore, it may be representative for the Southeast Asian English learners in the outer circle country. As for the impacts of English language proficiency on academic achievement, relevant studies have been found on Neumann et al. (2019), Lodhi et al. (2019), Farley et al. (2019), Kim et al. (2018), most of which are conducted via the method of quantitative data analysis. As for the definition of language proficiency, the seminal studies are the work of Casale \& Posel (2011) which defined language proficiency as the self-reported ability to 
read and write. Di Paolo (2011) held that language proficiency was the ability to speak and write, they viewed proficiency as the ability to organize language to carry out a variety of communication tasks. English language proficiency could be recognized from a narrow focus on the English language. The terms "English language proficiency" and "English language competence" are used interchangeably in many contexts. For this paper, English language proficiency has been defined as the ability of students to use the English language to make and communicate meaning in spoken and written contexts while completing their university studies. These uses include simple tasks such as discussing work with classmates and complex tasks such as writing academic papers or delivering speeches to professional audiences. As for the English language and its relation to national identity, relevant studies have been found on Chang (2019), Sung (2019), Zwisler ( 2018), Agdeppa and Barrot (2018), Stille (2015), most of which studied the relations of the English language, identity, power, and intelligibility.

This study aims to explore the impacts of English language proficiency on academic achievement and identity in the Philippine ESL context, with mixed methods of both quantitative and qualitative data collection and ana. The quantitative questionnaire was designed to collect information on the participant demographics, the relevant information, to investigate the participants' (i) Years of learning at University; (ii) Years of learning English; (iii) First-year grade GPA ( a measure of a student's academic achievement at a college or university, calculated by dividing the total number of grade points received by the total number attempted). Using a Likert six-point scale, the data from the questionnaire was designed to elicit participants' reactions to their academic life as a student in the university and their ability to organize their study and life. Besides, the qualitative interview was conducted among the participants, aimed and to find the supporting details. From the perspectives of the participants, they conveyed their point of view on whether and how English language proficiency impact their academic performance, the in-depth interview was recorded on the process, and then after transcription from the audio-recordings, the qualitative data was obtained. The open-ended questions in the interview offered the participants' another opportunity to deliver more discursive and reflective comments on their opinions and choices. Thus, this study's mixed-methods approach yielded the results and provided both quantitative and qualitative basis for evaluation. It should be stressed that it is a small-scale study based upon a limited number of participants. Consequently, it is not generalizable; however, it offers insight into exploring the factors impacting academic achievement and identity construction in the Philippine ESL context. The research questions, which have guided this study accordingly, are in the following. 1. What is the relation between English language proficiency and academic achievement? 2. To what extent are you willing to communicate in English? 3 . What is the relation between English and identities?

\section{Literature Review}

Related to the studies on the relation between the English language and academic performance could be found in Neumann et al. (2019), which explored the relationship between language scores and the academic performance of undergraduate students during the first year of study. Geide-Stevenson (2018) found that English proficiency positively impacts academic performance, but at a declining rate. Cekiso et. al (2015) investigated the impact of English language proficiency on learners' academic achievement in four subjects in the South Africa ESL context. Cho \& Bridgeman ( 2012) studied the relationship of TOEFL scores to academic performance from American universities. Related to the studies on the relation between the English language and identity 
construction could be found in Sung (2019) which argued that mainland Chinese students' participation in L2mediated activities in the university could be understood as a complex, dynamic, situated and co-constructed process of negotiating access, competence, membership, positionality, identities and discursive practices associated with different communities. Zwisler (2018) held that EFL instruction over time increased the perceived worth of Colombian national identity significantly while slightly increasing the positive perception of regional identity over the course of three years and that national language identity increased. Agdeppa (2018) explored how the participants perceive their identity as English language users and highlighted the need to vigilantly scrutinize how issues of language, identity, and intelligibility impact Filipino English teachers. Kohn (2018) argued for the social constructivist concept of his English as a basis for understanding ELF competence development and the tensions surrounding the relationship between ELT and ELF, from discrepancies in his ELF identity as a speaker of English with ELT roots in a German secondary school. Harvey (2016) theorized the relationship between language and intercultural learning from a Bakhtinian dialogic perspective, based on the language learning story of Federica, a mobile student in UK higher education. Otsuji \& Pennycook (2013:87) held that the appearance of World Englishes is regarded as the "pluralization of singular entities" encapsulated in the - es of Englishes. World Englishes has made it capable of expressing different national identities through the use of the English language. Pavlenko $(2003: 298)$ argued that "Classroom discourses play an important role in shaping students' membership in imagined communities and legitimizing new identity options”. The imaginative constructions of self can impact a learner's identification of his past and present experiences and provide a framework from which to interpret conflicts and see them as sites for change. Norton and McKinney (2011:76) assumed that imagined communities are not geographically restricted and can include "future relationships that exist only in the learner's imagination, as well as affiliations-such as nationhood or even transnational communities - that extend beyond local sets of relationships." Post-colonial Southeast Asian nation-states, have kept particular "nationalist imaginations" by applying explicit or implicit language policies, which include how to balance the spread of English and mother tongue of different ethnic groups since English is regarded as the language of modernity par excellence, while the trend of the indigenous languages are taken as the capital to maintain their own unique identities in the multi-ethnic and multi-lingual "imaginary community". As most of the relevant studies focused on how to manage the relationship between English and the local Asian languages needs to be deeply considered. For better development, different nation-states have applied and changed their language policies according to their unique histories. Language is first and foremost a social practice; L2 narratives are considered important social practices by telling and retelling their learning experiences through which imagined identities are evaluated and enacted.

Most prior studies reviewed the participants' English language proficiency as a predictor of academic achievement in the participants' study. Disproportionately little attention has been given to the roles and functions of the English language and its relation to the identities negotiation in the Philippines. To address this void, in this study, we make a contribution to the field by investigating the relationship between English language proficiency and academic achievement and identities negotiation in the Philippine ESL context, transposing the insights to understand the Filipino college students' opinions on the research topic. More researches are needed to describe multiple cases of participants' performance in English as a medium of instruction environment during regular academic years; and more factors that impact the participants' academic achievement, aside from their English language proficiency, should be taken into consideration in exploring the relation between English and academic attainment. Moreover, the Filipino participants' English language proficiency in English outer circle 
country of the Philippines in Southeast Asia, the relation between the English language proficiency and their self and social identities remain little explored; consequently, we make a further contribution to the literature by exploring links between the English language and the participants' identities, which have not yet been investigated previously. In order to address the issues mentioned above, the current study was designed to explore the undergraduates of different grades, and the participants of different majors are included. In this study, besides years of learning at university and years of learning English, the first-year GPA is taken as an English language proficiency measure to shed additional light on testing how well the participants' English language proficiency is.

\section{Methods}

Mixed methods were applied in this study; the quantitative research method is used to conduct questionnaires and then analyse the data collected. The qualitative research method is used to examine the relationship between English language proficiency and identity construction within a limited temporal period. Data collection involved two instruments: a preliminary questionnaire with 5-Likert scales and the in-depth interviews, which last at least an hour for each participant. Sequentially, participants were first provided with the questionnaire and allowed sufficient time to familiarize themselves with the topic at hand and reflect on their personal experiences, beliefs, behaviors, roles and identities when they use the English language. Upon submission of the completed questionnaire, interviews were scheduled ranging from one to two hours, on average, as interview data can both illustrate and illuminate questionnaire results and can "bring research study to life” (Dornyei \& Taguchi 2013 : 110). In this study, centering around the three research questions, more detailed questions are designed for the process of interview, which has been recorded with the mobile phone by the researchers, which help to gain a better understanding of the participants' point of view with the qualitative component, from their explanation and illustration of each designed question items, thereby adding the authentic flesh to the bone. With an attempt to fill gaps and provide a detailed examination of the relationship between the English language proficiency and academic achievement and identities construction and negotiation among English users in the ESL context.

The participants of the study are the undergraduate students who are the freshman or sophomore studying at the university for one or two years with different majors, in which Communication Arts, Marketing Management, Psychology, International Auditing, Business Management, Information Technology, International Studies, and Political Science are concerned. Analysis of the in-depth interview and retrospection reveals the opportunities and challenges that the English language proficiency would bring to the participants and how it constructs and negotiates their identities locally. Participants were selected at random from the undergraduate students, all of whom have learned the English language over ten years in either English as second language contexts (ESL) or contexts in which English is a medium of instruction. Given that all participants had spent at least one year in the college (the majority in English-speaking campus or studying in English medium school), all participants were fully able to communicate in English and preferred speaking in English to the researchers ( two teachers at the university). Read the following Table 1.

Table1 Participant Demographics

\begin{tabular}{|c|c|c|c|c|c|c|}
\hline Name & Gender & Age & Major & $\begin{array}{c}\text { Years of learning } \\
\text { at University }\end{array}$ & $\begin{array}{c}\text { Years of Learning } \\
\text { English }\end{array}$ & 1 st year GPA \\
\hline Mary & Female & 19 & Communication Arts & Sophomore & 15 & 3.5 \\
\hline
\end{tabular}


NEXT

\begin{tabular}{|c|c|c|c|c|c|c|}
\hline Name & Gender & Age & Major & $\begin{array}{c}\text { Years of learning } \\
\text { at University }\end{array}$ & $\begin{array}{c}\text { Years of Learning } \\
\text { English }\end{array}$ & 1st year GPA \\
\hline Mark & Male & 18 & Marketing Management & Freshman & 16 & 4 \\
\hline David & Male & 18 & Psychology & Freshman & 15 & 3.5 \\
\hline Thomas & Male & 18 & Communication Arts & Freshman & 13 & 3.0 \\
\hline Ana & Female & 18 & Internal Auditing & Freshman & 14 & 4 \\
\hline Mathew & Male & 20 & Business Management & Sophomore & 16 & 3.45 \\
\hline Ryan & Male & 18 & Information Technology & Freshman & 13 & 3.5 \\
\hline Cindy & Female & 18 & International Studies & Freshman & 13 & 3.35 \\
\hline Wendy & Female & 18 & Communication & Freshman & 13 & 4.45 \\
\hline Mike & Male & 22 & Political Science & Senior & 18 & 3.0 \\
\hline
\end{tabular}

Table 1: A table on the detailed information on the participants' demographics

Note to Table 1:

i ) Different part in this table indicates the relevant information on the participants' selected in the study.

ii ) Source: Own elaboration.

Table1 provides the background demographic data of the participants. The research proposal has been inspected by the scientific research department and foreign affairs department of the university. We investigate the survey to ensure that the research ethics are to be met. The participants were recruited at random among the undergrads. The researchers elucidated the objectives of the in-depth interview and the following-up retrospection. For the participants in this study, familiarity with the researchers allowed for greater sharing of personal experiences and a heightened sense of comfort and understanding. Likewise, familiarity with the participants allowed the researchers to better understand the contextual nuances of which the participants delivered in their interview. The respondents have conducted the interview in English, and all the participants expressed a preference to proceed in English.

With the application of the two instruments, a preliminary open-ended questionnaire and an in-depth interview, the qualitative method was used to collect data to examine the relationship between English language learning/use and identity within a limited temporal period. Sequentially, participants were first provided with the questionnaire and allowed sufficient time to familiarize themselves with the topic at hand and reflect on their personal experiences, beliefs, behaviors, and roles. Upon submission of the completed questionnaire, interviews were scheduled, ranging from 1 to 2 hours, on average. During the interview process, the participants were allowed to refer to their questionnaire while the researchers drew from semi-structured interview techniques to allow the participants to elaborate and clarify. Voice-recording software was used, and the in-depth interviews were recorded for respondent validation and transcription purposes.

In the in-depth interview, the participants were required to explain or illustrate their answers to the questionnaire items, thereby adding authentic resources to their choices. This is a sequential explanatory design to implement and analyze the data collected, which attempted to enrich the final findings considerably. In more detail, the participants were asked to go through their own responses with an interviewer and provide retrospective comments on the reason for their particular answer to each item. In this way, the participants' responses serve as prompts for further open-ended reflection. Frankly speaking, the participants may have 
different perceptions under identical circumstances of how well the English language proficiency have impacted their academy and daily communication. However, as Bleakley \& Chin (2010) hold that subjective questions are typically found to be highly correlated with their scores from tests designed to accurately measure language skills as well as functional measures of language skills'. More information will be delivered in the following findings.

This study explores the English language proficiency in relation to the participants' academic achievement, future career development, identities construction and negotiation. The participants' responses to the questions in the in-depth interview and retrospection show that the significant correlation between years of learning English and years of learning at the university and the participants' first-year GPA (Grade Point Average) ; the English language proficiency is regarded as one of the significant capitals; the English language is dominant in the linguistic marketplace. Thus there is an obvious relationship between English language proficiency and academic achievement, and there is a significant correlation with one's future job and career development; English and national identity construction and negotiation; the use of English in the social aspects. Among the correlations observed in Table 1 and the follow-up interview and retrospection, with the detailed questions designed for the process of interview, the Questions and Answers format was applied in collecting and analysing the recording material in the following sections.

\section{Findings and Discussions}

\subsection{Not always a clear relationship between English language proficiency and academic achievement}

Although this research does find that the longer years of their learning English, the higher score they've got in their required subjects; the longer years of their schooling at the university, the higher their first-year GPA. Since on the tertiary education level, all the colleges and universities take EMI (English as a Medium of Instruction ), as English is the language of modernization and technology. It needs to be stressed that both media of instruction, English and Filipino, are languages that most Filipino children meet for the first time on their first day in school (Kirkpatrick 2010:39). In this study, all the ten participants in the follow-up interview said that they had learned English since three years old when they were in the kindergarten, therefore, when they study in the university as a freshman; it has been at least 15 years that they have learned the English language. English in the Philippines is the former suzerain language, the official language, the medium of instruction, the language of modernization and knowledge dissemination, and thus has represented a major part of the school curriculum. Accordingly, a significant correlation between years of learning English and the participants' 1st year GPA could be found in the research; in a similar vein, a significant correlation between years of learning at the university and the participants' 1 st year GPA could be seen, as the participants' performance in the required subjects were measured through their end of the first-year results. The positive and statistically significant coefficient for the length of studying in English as a medium of instruction (the years of learning in the university) indicates that longer exposure to the English language firmly favors its academic achievement. Specifically, it is shown that the longer they have studied in the university, the higher the GPA they will get. Moreover, the participants with higher English language proficiency are more open to adapting to academic life and have a better well-being than those with lower English language proficiency. However, when it comes to the relation between English language proficiency and academic achievement, this research found that it was not necessarily the case that there exist clear correlations between the two variables, which is much consistent with the research findings of Neumann et 
al. (2019), but is inconsistent with the finding of Poyrazli and Kavanaugh (2006), which found that low academic achieving reported lower levels of English proficiency and greater overall adjustment strain, and the researches showing a relationship between English proficiency and academic performance in international students (Poyrazli, Arbona, Bullington, \& Pisecco 2001; Zhang \& Brunton 2007). In the current study, we hold that more factors should be taken into consideration when exploring the relationship between the participants' academic achievement and their English language proficiency. Factors such as motivation, attitude, study methods, academic self-concept may provide additional information that helps predict the participants' academic achievement. It will be further explored in the following series of research projects on Southeast Asian Englishes.

\subsection{Willingness to communicate in English}

The research found that all the participants are willing to communicate in English, both in academic contexts and in their daily lives. English has played a significant role and has functioned as a pragmatic instrument in the participants' academic performance, especially in the Philippines ESL context, where English is the official language and the highly-valued language frequently used in nearly all social domains of society, thus it is considered to be the significant social capital, which resources made available through social networks and group membership. The English language is the medium of instruction at the college level, a vital factor in the academic context, and it is the main vehicle that carries the cultural knowledge and social representations present in a community. To Filipino college students, English is a kind of valued most human resource. In the domain of education, the English language is the medium of instruction in schools of all levels; English language proficiency is highly valued because it is the form of knowledge, skill, and education. The prevalence of English in professional contexts required demonstrations of their English fluency. Hence, Filipino (or other vernaculars) and English bilinguals to interact naturally and comfortably in English is a sign of cultural capital, which shows the social status and a highly desired skill they possess in the local contexts, according to Bourdieu (1986). High English language proficiency is taken as the economic capital which ensures a good-paid job and wealth in money and property, as not all forms of language have the same "value" in the market since their evaluation depends on the power and authority of the groups which use them.

During the interview, centering on the research questions, questions in detail have been designed. When asked, " To what extent are you willing to communicate in English? What are your goals, and how do you think English will help you achieve these goals?" Most of the participants' responses are "Very much”, which is inconsistent with MacIntyre et al. (2011), who had carried out the qualitative studies by revealing that L2 learners' willingness to communicate in a foreign language is context-dependent and will change based on how learners interact with their environment. In the current study, impressive are the following responses which had been recorded and transcribed from the interview:

Ana: I am willing to communicate in English very much, ah, because I want to study abroad, I will get a $\mathrm{PhD}$ in the US, so English language proficiency is the first and foremost requirement.

Wendy : English is my native language, it is one of the commonly used languages in the world, and it will help me communicate with others better. English was chosen as the Philippine's national language as a way to bridge the gap among different ethnic groups.

Mark: English is Philippine's main language of communication and a mandatory language to learn in school, so I have communicated in it with my teachers and classmates at school and communicate with my parents in English at home for many years. 
From the answers in the in-depth interview with the participants, we could see that the English language proficiency that the participants possess help them to account for the ways in which their life trajectories become structured. Specifically, the English language is a key aspect of cultural capital that the ten participants possess and pursuit for further learning through their everyday living in the local contexts, which is more highly valued than the other languages in their linguistic repertoires. Thus they showed their willingness and eagerness to communicate with their teachers and counterparts in English in the academic contexts, and some participants even communicate with their family members at home.

In response to the detailed questions "Please describe your English language learning experience? How much time, effort, and/or financial resources have you invested in learning English?", the following three answers were :

Mary: Most of the time was self-study, so it did not cost much, I practiced writing and reading with sample tests, continually in 6 months before I took the first TOEFL iBT. Then it took another six months to review and take the test again. As I am a sophomore, studying abroad in the US is my goal and I have prepared from now on.

Ryan: Throughout my whole education life ( since kindergarten), I have been learning English. Besides, I also took up tuition classes to score better in my English subject.

Mathew: It is part of our school curriculum in the Philippines. Resources put in would be school fees paid, which are highly subsidized by the government and scholarships I've received. Years of learning English would be about 16 years.

From the answers, it is clear that most of the participants have spent a lot in the investment of learning English due to its special value in all the social aspects. Especially nowadays in the era of globalization, English is a lingua franca (Jenkins 2007), and widely used all over the world, the English proficiency is regarded as one of the most important human resources.

When asked, "Are you satisfied with your English language proficiency? What degree of English language learning fluency do you hope to achieve? What can or will you do to attain this goal?" The participants' responses changed from "not satisfied", "satisfied", to "very satisfied". The following are the three answers from the participants :

David: I am not satisfied with my English speaking. I need to speak more fluently to be more confident when participating in class discussions. I am thinking about an English chatting room in my university, a series of seminars on certain topics have been held, and participants are encouraged to make an academic contribution of their points of view on the relevant topics.

Thomas: Yes, I am satisfied. I would like to be better (learn more vocabulary etc.). I feel that I can attain this goal by reading more.

Cindy: Yes, I'm very satisfied with my English proficiency. According to the English level issued by the Department of Education, my English language proficiency is Upper-Intermediate level and over.

In the questionnaire that the participants conducted before this interview, the multiple choices of this question item are the following four distribution of responses: A. 'very well' , 76.8\%; B. 'well' , 10.2\%; C. 'sufficient', $8.3 \%$; D. 'need to improve' , 4.7\%. See the following Figure 1. It must be noted that respondents are asked to self - assess whether they possess a satisfactory skill level in the four different areas, including reading, speaking, listening and writing. That is to say, in the Bilingual Education Policy (BEP) issued by the Department of Education in the Philippines, English is a dominant language on education. It is not only a subject 
but also a medium of instruction. Therefore the English proficiency of the participants who have been learning English at least for 15 years from kindergarten to university could be very well, which means fluency in the four skills mentioned above. Read the following Figure 1.

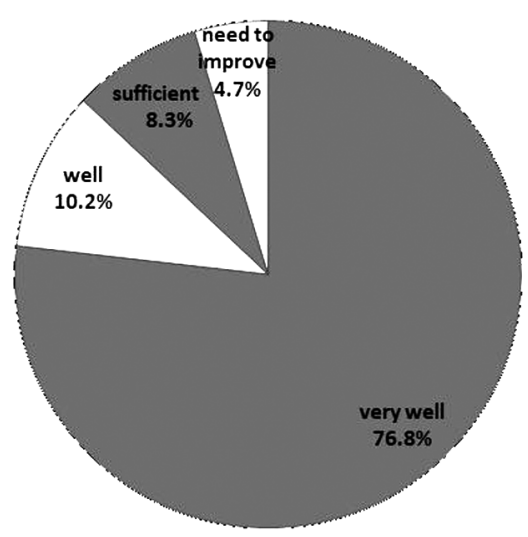

Figure 1 A pie chart on the percentage of the four choices

Note to Figure 1:

i) Different part in this pie chart indicates the percentage of the four choices that the participants selected in the survey.

ii) Source: Own elaboration.

In response to the questions, "Do you think your English proficiency affects how you perceive yourself and how others perceive you?” The participants' responses varied from different individuals:

Mary: Yes, English proficiency is extremely important when we study abroad, especially at the graduate level. Low English speaking skill is a constraint to discuss in class, to share the idea. It sometimes causes a bad mood, and I was sometimes disappointed when I could not express what I wanna say. When we cannot participate in the class, other people sometimes might think that I am not well prepared, not socialized, not confident.

Mark : Yes. I feel I am an intelligent Filipino when I speak English, and I am perceived as a well-educated person by others.

Mike: English is Philippine's official language. It does reflect one's intellectual ability.

It is obvious that in the Philippines, English language proficiency is a basic requirement for both academic life and daily communication in all social domains. Specifically, the graduates seek after positions in the large international companies with its Asia Pacific headquarters set in Manila, and the high English language proficiency will ensure a well-paid job in the labor market. That is why all the participants in the interview said that they are willing to communicate in English, and they have spent great efforts to advance their English proficiency because it relates to academic performance, employment opportunities and social status. In order to fulfill the academic capacity on the one hand and to find a well-paid job in a fiercely competitive job market, it is highly needed to be fluent in communicating in the English language.

\subsection{English in relation to identities}

The study found that the English language is in relation to the participants' identities construction and negotiation. English is taken as the assets for better empowerment for the college students, and it is consistent with the research of Piccardo (2013), which held that the students may develop a greater critical awareness of 
their own culture and cultural identity and may empower them with self-esteem to potentially optimize learning. To elucidate the relations, this study explores how the participants perceive their identities as English language users. In speaking English, they think they are the Filipinos, and they feel proud that they could use the English language freely and fluently, as English is considered to be a symbolic capital that delivers prestige and honor in society and communication. As English is quintessential to the complex process of identity construction and the feeling of belonging to a group (Heller 2008), which supports the relevance of study processes in the linguistic domain, it is true that the English language has regularly been supposed to have a highly important role to play in the great efforts of constructing and maintaining the identities in the Philippines, the English language expression and identity occurring mainly in private or professional circumstances. It is consistent with Simpson (2007: 1). He believes that "a common language can assist in the construction of a geographically widespread, imagined community of speakers and the building of nation-like polities, providing linguistic links are also reinforced with other shared cultural properties”. In this study, the participants expressed their pride in the English language proficiency they have gained from years of learning, and said that they felt they were the Filipinos when they use the English language, they perceived their English language proficiency in academy and identity construction and negotiation and said that English had played multiple roles and functions in the academic context and daily communication, as English is not only the national language, official language, and medium of instruction in education, but also English has shaped self and social identities through the actual use of it.

When asked, "How do you decide which language to use when speaking to someone? When do you use your mother tongue? When do you use English? When do you switch? And Why? The typical answers from the participants included:

Cindy: I just use my mother tongue with family members. Otherwise, I use English with everybody here in the school system.

Ana: Depends on the language that the person uses when he/ she first met me. I use my mother tongue to my parents/ relatives, and I use English to my peers, colleagues and siblings. I switch quite often as I am more comfortable with communicating in English, which enables me to construct my self and social identities of a Filipino in the globalization era.

Mike: I think it's a matter of who is more comfortable speaking their mother tongue, assuming the person I speak to does not usually speak English. If that person is more comfortable speaking English as opposed to me speaking Mandarin (my mother tongue), then it's likely that we will communicate in English.

Post-structuralism conceptualizes identity as something that is in constant process and argues that language is the principal means through which identity is forged (Swaan 2004:140), that is to say, identity is a dynamic process rather than something fixed, and thus identity could be constructed and negotiated with the language use. From the answers of the participants, we could see the change and fluidity rather than stability in the language choice when they meet different people in the communication according to the context. If language expresses one's identity, then the participants' subjectivity preferred to describe the individual's sense of who he or she is. It is consistent with Weedon's (1987:32) research which holds that "Subjectivity is referred to the conscious and unconscious thoughts and emotions of the individual, her sense of herself and her ways of understanding her relation to the world", this qualitative interview also explored on the relationship between language and identity from the perspective of individual's language choice.

When asked, "Have you ever thought about the role of English in your life? Have you ever thought about how your life would be different if you didn't speak English?" The participants' main answers are the following: 
Mary: With good English skills, I had a better job. Without English, maybe I don't have the ambition to study abroad in the US. In communicating with others in English, my self-identification of a modern Filipino arises.

Mathew: No, I have not thought of it. I feel that I would be better in my mother tongue at home with my parents, but when it comes to school, I use English instead.

Mark : English plays a very big role in my life because $95 \%$ of my communication is done using English. It would be much more difficult to get around the Philippines without speaking or understanding English.

Comparatively, the English language has played a more important role in the Outer Circle countries than in the Expanding Circle countries in Southeast Asia. As English is a second language in outer-circle countries, thus L2 identity negotiation in local contexts is a complex process raising the question of L2 identity options. In this interview, most of the participants said that they would like to use English on public occasions, they were fully aware of the effect of English on their identities as Filipino nationals. This is much in the same vein with the conclusion that Kramsch (2009:63) drew, which holds that for some participants, English use in a public space created the feeling of "self-enhancement", re-positioning them as educated and "part of the elite". However, as we could see from Mathew's answer mentioned above, for some participants, contrary to Bourdieu's (1987) capital theories, which held that English is both the language capital and the cultural capital, this was perceived as an imposition of their ethnic, cultural identities, that is why some participants felt their self-identity when they communicate with their parents in their mother tongues. Nevertheless, as proficient English language users, the participants knew better that they need to transform their social identity into their expected identity in most cases.

\section{Conclusion}

In recent years, the study of language and identity construction and negotiation in the ESL context has enjoyed significant attention and has been the subject of substantial inquiry. The use of subjective evaluations is standard in this study, partly due to the high costs of test-based assessments of language ability and time limit staying in the Philippines. Inspired by the latest research from the perspectives of education, psychology, and other interdisciplinary studies, the further research will explore the relevant issues of the models of academic self -concept (ASC), which emphasize the roles of social and dimensional comparisons in ASC development, and will be taken into consideration in the following series research.

The present study reveals the opportunities and challenges that English language proficiency would bring to the participants and how it constructs and negotiates their identities locally. It attempts to explore the relation between English language proficiency and the students' academic performance during the undergraduate program. Although the study was carried out on a small scale, it has shown its findings on the main three points; specifically, which offered insight into the identity construction and negotiation in the Philippine ESL contexts. The findings of this study show that English is widely used in all social aspects, including the academy, future career and development, and daily life communication. All participants hold that they use English nearly in all social aspects, and most respondents commented that English use was not typically confined to academic and language-institution settings, but prevalent in all the social domains, greater fluency in the English language is expected to enhance productivity in the job by making the employees more efficient in performing particular tasks or by reducing the cost of communication within the firm. The participants expressed their desires for more opportunities to use the English language in all social aspects because they felt their self and social identities 
whenever they used English. They are proud of themselves and their social recognition as Filipinos with high English proficiency in society. More exploration on the topic will go on with further research.

\section{References}

Agdeppa, J. Y and Barrot, J. S. (2018). Language, identity, and intelligibility: An analysis of Filipino EFL teachers' perspectives. Advanced Science Letters. 24(1), 2347-2352.

Bleakley, H. and Chin, A. (2010). Age at arrival, English proficiency, and social assimilation among US immigrants. American Economic Journal: Applied Economics, 2, 165-92.

Bourdieu, P. (1986). The form of capital. In J. G. Richardson (Ed.), Handbook of theory and research for the sociology of education. New York: Greenwood Press.

Casale, D. and Posel, D. (2011). English language proficiency and earnings in a developing country: The case of South Africa. Journal of Socio-Economics, vol. 40, 385-393.

Cekiso, M., Tshotsho, B. and Masha, R. (2015). English language proficiency as a predictor of academic achievement among primary English first additional language learners in South Africa. International Journal of Educational Sciences. Vol. 9 (3) , $325-333$.

Di Paolo, A. (2011). Knowledge of Catalan, public/private sector choice and earnings: Evidence from a double sample selection mode. Hacienda Pública Española, vol. 197(2), 9-35.

Dornyei, Z. \& Taguchi., T. (2013). Questionnaires in second language research: Construction, administration, and processing. Beijing: Foreign Language Teaching and Research Press.

Harvey, L. (2016). I am Italian in the world: A mobile student's story of language learning and ideological becoming. Language and Intercultural Communication, 3, 368-383.

Heller, M. (2008). Language and the nation-state: Challenges to sociolinguistic theory and practice.Journal of Sociolinguistics, 12 (4), 504-524.

Jang, E. and Brutt-Griffler, J. (2018). Language as a bridge to higher education: a large-scale empirical study of heritage language proficiency on language minority students' academic success. Journal of Multilingual and Multicultural Development, 40(4), 322 -337 .

Jenkins, J. (2007). English as a lingua franca: Attitude and identity. Oxford: Oxford University Press.

Kavanagh, L. (2020). Academic self-concept formation: Testing the internal/external frame of reference model, big-fish-little-pond model, and an integrated model at the end of primary school. European Journal of Psychology of Education, 135 (1) , 93-109.

Kim, T. Y. and Kim, J. Y. (2018). A qualitative inquiry on EFL learning demotivation and resilience: A study of primary and secondary EFL students in South Korea. Asia-Pacific Education Researcher, 57, 55-64.

Kirkpatrick, A. (2010). English as a Lingua Franca in ASEAN: A multilingual model. Hong Kong: Hong Kong University Press Kohn, K. (2018). MY English: a social constructivist perspective on ELF. Journal of English as a Lingua Franca, 7 (1), 1-24.

Lodhi, M. A., Zafar, Z. and Akhtar, N. (2019). Impact of English teachers' behavior on English proficiency skills of ESL learners at secondary level. International Journal of English Linguistics, 9, 277-292.

MacIntyre, P. D., Burns, C. and Jessome, A. (2011). Ambivalence about communicating in a second language: A qualitative study of French immersion students' willingness to communicate. The Modern Language Journal, 95(1) , 81-96.

Neumann, H. Padden, N. and McDonough, K. (2019). Beyond English language proficiency scores: understanding the academic performance of international undergraduate students during the first year of study. Higher Education Research \& Development, 38, $324-338$

Piccardo, E. (2013). Plurilingualism and curriculum design: Toward a synergic vision. TESOL Quarterly, 47 (3), $600-613$.

Poyrazli, S., Arbona, C., Bullington, R. and Pisecco, S. (2001). Adjustment issues of Turkish college students studying in the United States. College Student Journal, 35, 52-63.

Poyrazli, S. and Kavanaugh, P. R. (2006). Marital status, ethnicity, academic achievement, and adjustment strains: The case of graduate international students. College Student Journal, 40, 767-780. 
Simpson, A.(2007). Language \& national identity in Asia. Oxford University Press.

Stille, S. (2015). Identity as a site of difference: Toward a complex understanding of identity in multilingual, multicultural classrooms. Intercultural Education, 26, 483-496.

Sung, C. ( 2019 ). Negotiating participation and identity in a second language: Mainland Chinese students? English learning experiences in a multilingual university in Hong Kong. Research Papers in Education. Article.

Swann, J., Deumert, A., Lillis, T., and Mesthrie, D. (2004). A dictionary of sociolinguistics. Tuscaloosa: The University of Alabama Press

Weedon, C.(1987). Feminist practice and poststructuralist theory. Oxford: Basil Blackwell.

World Bank, https://www.ethnologue.com/country/thephilippines

Zhang, Z. \& Brunton, M. (2007). Differences in living and learning: Chinese international students in New Zealand. Journal of Studies in International Education, 11, 124-140.

Zwisler, J. (2018). The effects of English as a foreign language learning on the perception and value of regional and national identity in Colombia: A cross-sectional study. Íkala, Revista de Lenguajey Cultura, 23, 255-268.

(Editor: Jasmine) 